\title{
Growth of laser damage in fused silica: diameter to depth ratio
}

M. A. Norton, J. J. Adams, C. W. Carr, E. E. Donohue, M. D. Feit, R. P. Hackel, W. G. Hollingsworth, J. A. Jarboe, M. Matthews, A. M. Rubenchik, M. L. Spaeth

November 6, 2007

SPIE - Boulder Damage Symposium

Boulder, CO, United States

September 24, 2007 through September 26, 2007 
This document was prepared as an account of work sponsored by an agency of the United States government. Neither the United States government nor Lawrence Livermore National Security, LLC, nor any of their employees makes any warranty, expressed or implied, or assumes any legal liability or responsibility for the accuracy, completeness, or usefulness of any information, apparatus, product, or process disclosed, or represents that its use would not infringe privately owned rights. Reference herein to any specific commercial product, process, or service by trade name, trademark, manufacturer, or otherwise does not necessarily constitute or imply its endorsement, recommendation, or favoring by the United States government or Lawrence Livermore National Security, LLC. The views and opinions of authors expressed herein do not necessarily state or reflect those of the United States government or Lawrence Livermore National Security, LLC, and shall not be used for advertising or product endorsement purposes. 


\title{
Growth of laser damage in fused silica: diameter to depth ratio
}

\author{
Mary A. Norton, John J. Adams, C. Wren Carr, Eugene E. Donohue, Michael D. Feit, Richard P. \\ Hackel, William G. Hollingsworth, Jeffrey A. Jarboe, Manyalibo J. Matthews, Alexander M. \\ Rubenchik and Mary L. Spaeth \\ Lawrence Livermore National Laboratory, 7000 East Avenue, Livermore, CA, USA94550
}

\begin{abstract}
Growth of laser initiated damage plays a major role in determining optics lifetime in high power laser systems. Previous measurements have established that the lateral diameter grows exponentially. Knowledge of the growth of the site in the propagation direction is also important, especially so when considering techniques designed to mitigate damage growth, where it is required to reach all the subsurface damage. In this work, we present data on both the diameter and the depth of a growing exit surface damage sites in fused silica. Measured growth rates with both $351 \mathrm{~nm}$ illumination and with combined $351 \mathrm{~nm}$ and $1054 \mathrm{~nm}$ illumination are discussed.
\end{abstract}

Keywords: Laser damage, laser damage growth, laser damage growth threshold, UV fused silica.

\section{INTRODUCTION}

Neodymium glass laser systems, operating at $1.053 \mu \mathrm{m}$, commonly utilize frequency conversion to output harmonic wavelengths at $527 \mathrm{~nm}$ and $351 \mathrm{~nm}$. Laser beam delivery systems downstream of the frequency convertor frequently use fused silica lenses and/or beam splitters which may have all three wavelengths present on both the input and output surfaces. The growth of laser damage on the exit surface of fused silica has been studied at these three wavelengths and combinations of these wavelengths. ${ }^{1,2,3,4}$ For these wavelengths, it has been established that the lateral diameter of laserinitiated damage located on the exit surface of a fused-silica optic grows exponentially with laser shot number. Changes in diameter with increasing shot number are certainly accompanied with changes in the longitudinal structure of the damage site. Knowledge of the extent of both the laterally and longitudinally damaged material is of interest to mitigation schemes and to potential refinishing of an optic.

The primary objective of this experiment is to measure both the lateral and longitudinal growth of laser-initiated damage on the exit surface of fused silica at both $351 \mathrm{~nm}$ and combined $351 \mathrm{~nm}$ and $1053 \mathrm{~nm}$ wavelengths. Early work ${ }^{1}$ suggested that the longitudinal growth had a linear dependence on shot number. This work will simultaneously measure both the lateral and longitudinal growth characteristics of exit surface laser damage.

\section{EXPERIMENT}

\subsection{Laser system and experimental description}

Laser damage initiation thresholds are typically measured with small beam laser systems where the beam profile is Gaussian and of diameter less than 1-mm. To make measurements of laser damage growth that are relevant to large beam areas such as are found on high energy laser systems, it is necessary to use a beam with an area large relative to the initial damage size. At LLNL, a unique laser facility can provide a large area, $1053 \mathrm{~nm}$ beam, along with a high rep rate. The laser is the SLAB laser system ${ }^{5}$, a Nd:glass zig-zag slab amplifier, using SBS phase conjugation to produce a near diffraction limited $1053 \mathrm{~nm}$ output. As configured for these experiments SLAB provides a $20 \mathrm{~J}, 1053 \mathrm{~nm}$ output pulse, with a $13 \mathrm{nsec}$ FWHM near Gaussian shaped temporal waveform, at a rep rate of $0.3 \mathrm{~Hz}$. The rep rate is limited by the data collection rate, as the laser system can be operated at $4 \mathrm{~Hz}$. This beam is frequency converted to provide the $351 \mathrm{~nm}$ test beam.

The SLAB beam is image relayed at a size of $1.7 \mathrm{~cm}$ by $1.7 \mathrm{~cm}$ to the frequency converter system to produce $351 \mathrm{~nm}$ light. The frequency converter is a type I KD*P doubler followed by a type II KD*P tripler. The converted third harmonic and the depleted fundamental wavelengths are used in the growth measurements. Though each wavelength 
follows a different path to the beam combiner located before the test chamber, the individual path lengths are controlled to keep the arrival times simultaneous within a few nanoseconds. Three important characteristics of the test beams result from using this scheme: first, the depleted fundamental spatial profile tends to have better spatial uniformity than the unconverted beam, second, the temporal pulse width of the depleted fundamental is longer than the unconverted beam third, the relative polarizations of the frequency converted beam and the depleted fundamental are parallel to each other. Both wavelengths are spatially filtered before they are recombined at the sample chamber. The key components of the layout for these experiments with the SLAB laser are shown in figure 1. The sample is located in an image relay plane of the laser and the beam size for all wavelengths on the sample in the test chamber is nominally $5 \mathrm{~mm} \times 5 \mathrm{~mm}$. The beams are spatially and temporally overlapped at the sample. The laser is incident on the sample at $15^{\circ}$. The fluence of each wavelength is independently controlled with a polarizer/wave plate combination.

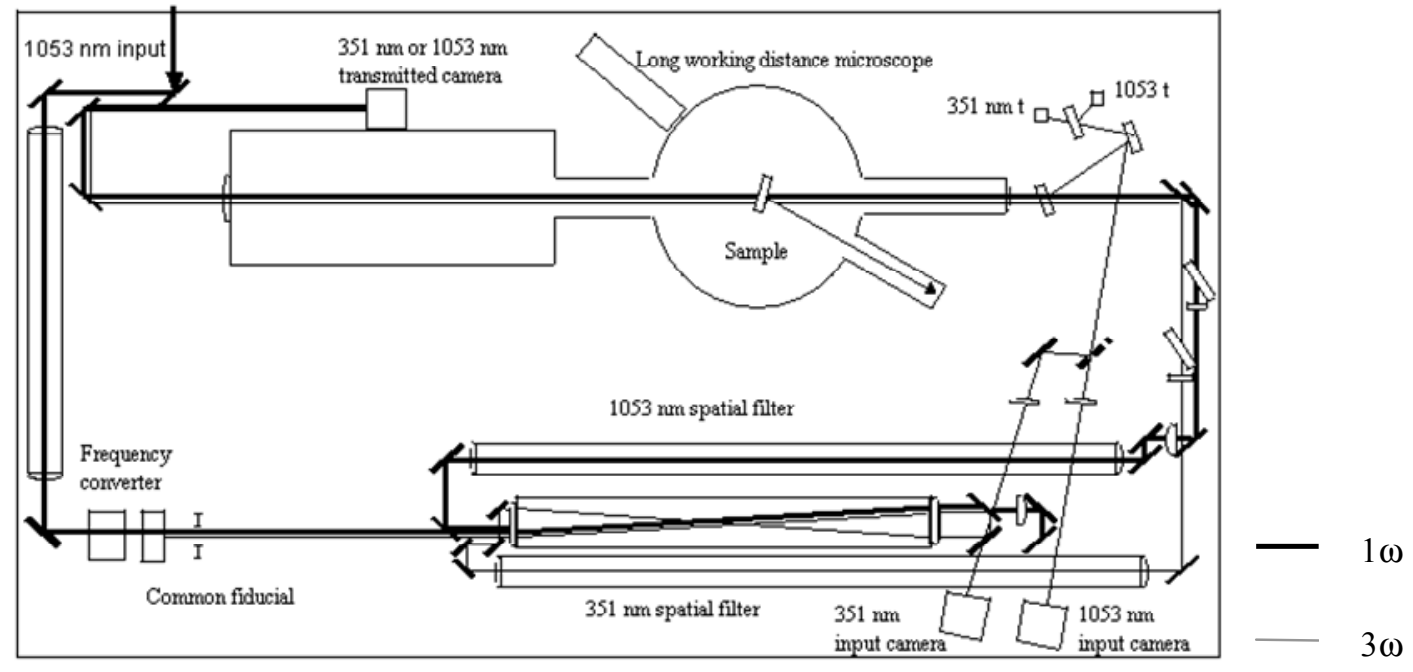

Figure 1. Schematic layout for the experiments.

The sample is housed in a stainless steel vacuum chamber, which is located in a class 100 area where samples up to $150 \mathrm{~mm} \times 150 \mathrm{~mm}$ in size are handled during loading. The tests are conducted in air, at 2.5 torr, by introducing dry filtered high purity air into the chamber after it is pumped out to vacuum.

Laser beam measurements for both wavelengths on the part include measurements of the temporal pulse shapes, energy, and incident beam spatial intensity distributions measured with 16-bit scientific-grade CCD cameras. The cameras are calibrated both for energy and for magnification and are used to set and record the fluence on the sample for each shot. Diagnostics to measure the growth include a white light illuminated, long working distance microscope and CCD camera and a scientific grade CCD camera recording the image of the damage site using the transmitted laser beam. In practice, the camera viewing the beam transmitted through the sample is used to locate the starting damage and the input cameras are used to set the local fluence in a 1-mm patch surrounding the site. The lateral growth of the damage site can be measured either from the transmitted camera or from the microscope. For the measurements reported here both the lateral and the depth measurements are made off line using a high resolution optical microscope. A typical image of the converted beam and temporal waveforms on the sample for the combined $351 \mathrm{~nm}$ and $1053 \mathrm{~nm}$ tests are shown in figure $2 \mathrm{a}$ and $2 \mathrm{~b}$ respectively. The calculated statistics for the $351 \mathrm{~nm}$ beam shown in figure 2a yield a contrast ratio (rms/average) of $18 \%$ over the central $60 \%$ of the beam area and $~ 8 \%$ in the 1-mm patch surrounding the growing site. The beam contrast for the depleted beam is somewhat better. Typical temporal waveforms are shown in figure $2 \mathrm{~b}$, with the average FWHM=11 ns for the $351 \mathrm{~nm}$ beam and $18 \mathrm{~ns}$ for the $1053 \mathrm{~nm}$ beam; also seen in the plot is the relative time of arrival of the two beams with the $1053 \mathrm{~nm}$ beam arriving approximately $2 \mathrm{~ns}$ before the $351 \mathrm{~nm}$ beam. 


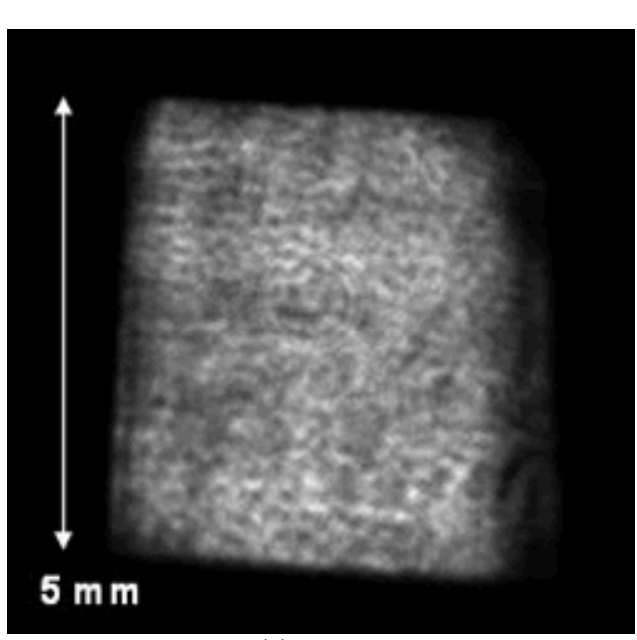

(a)

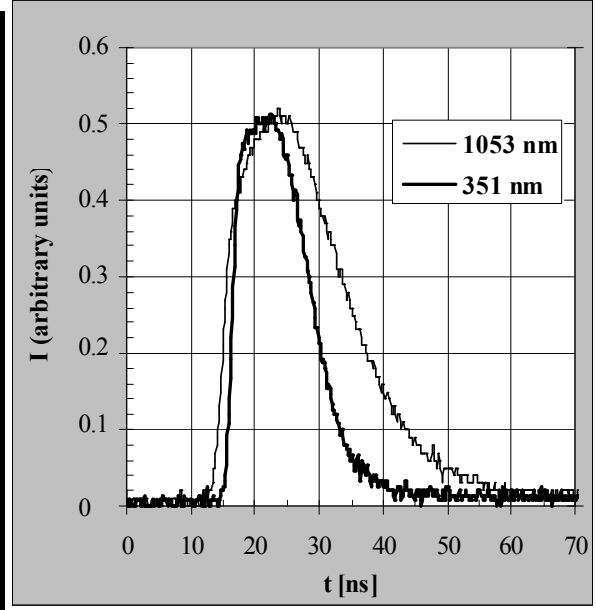

(b)

Figure 2. Typical $351 \mathrm{~nm}$ laser beam near field image (a) and temporal profiles for both wavelengths (b).

\subsection{Sample description}

The samples are fused silica, UV grade Corning 7980 with a SESO super polish. The 2-inch round, 1-cm thick, substrates were prepared with a chord edge finished with an inspection polish. This allowed viewing the damage from both the side and the surface. Laser damage was initiated off-line on the exit surface at $355 \mathrm{~nm}$ with a single shot at a fluence level in the 30 to $45 \mathrm{~J} / \mathrm{cm}^{2}$ range with a $7.5 \mathrm{nsec}$ FWHM Gaussian pulse. This fluence range produced damage sites ranging from a single pit to an array of 2 to 10 pits. The substrate geometry is shown in figure 3 .

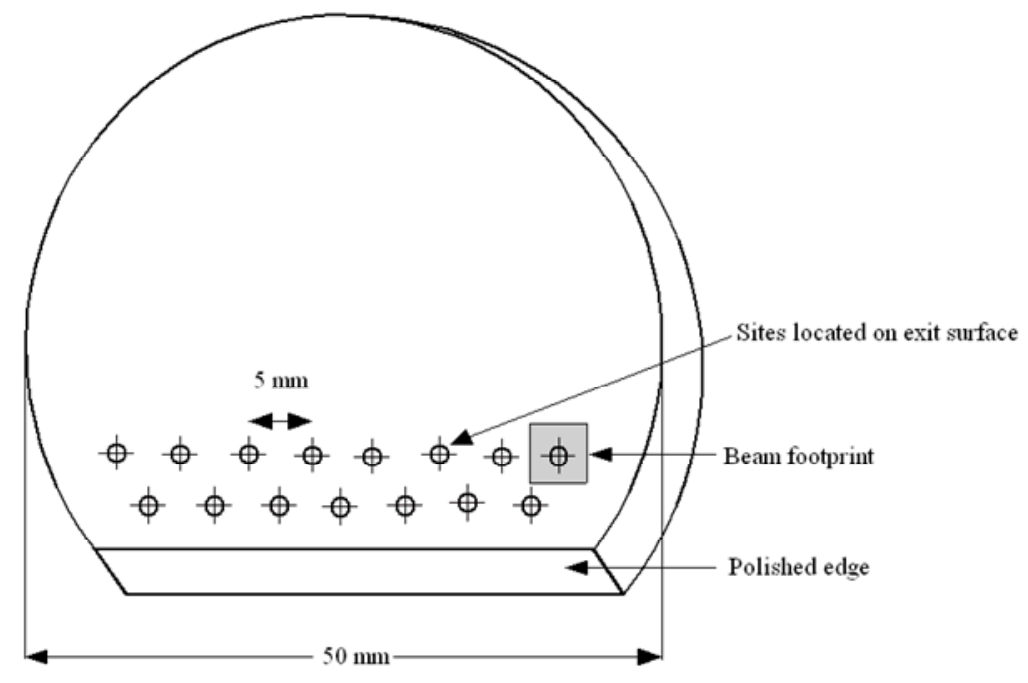

Figure 3. Sample geometry.

\section{EXPERIMENTAL RESULTS}

\subsection{Diameter and depth measurements}

The goal of this work is to obtain the growth rate of both the lateral size and the depth of damage into the material. A growing exit surface site typically consists of a central crater containing melted resolidified material and a network of fractured material surrounding the crater. A pair of microscope images, obtained after growing a site to nearly $700 \mu \mathrm{m}$, is shown in figure 4 . We define the surface area to be the entire surface area damaged including all the regions where cracks are visible, as shown in figure 4a. This area is used to calculate an effective diameter after each shot assuming a circular shape. For the depth measurements we distinguish two regions as shown in figure $4 \mathrm{~b}$. The first is the depth of 
the crater defined to be the distance from the optical surface to the bottom of the crater. We note that this distance is not always unambiguous in the side view images, so an additional measurement is obtained using the microscope focusing stage while viewing through the exit surface. The second region of interest is the depth of the cracks defined as the distance from the optical surface to the bottom of the deepest visible crack.

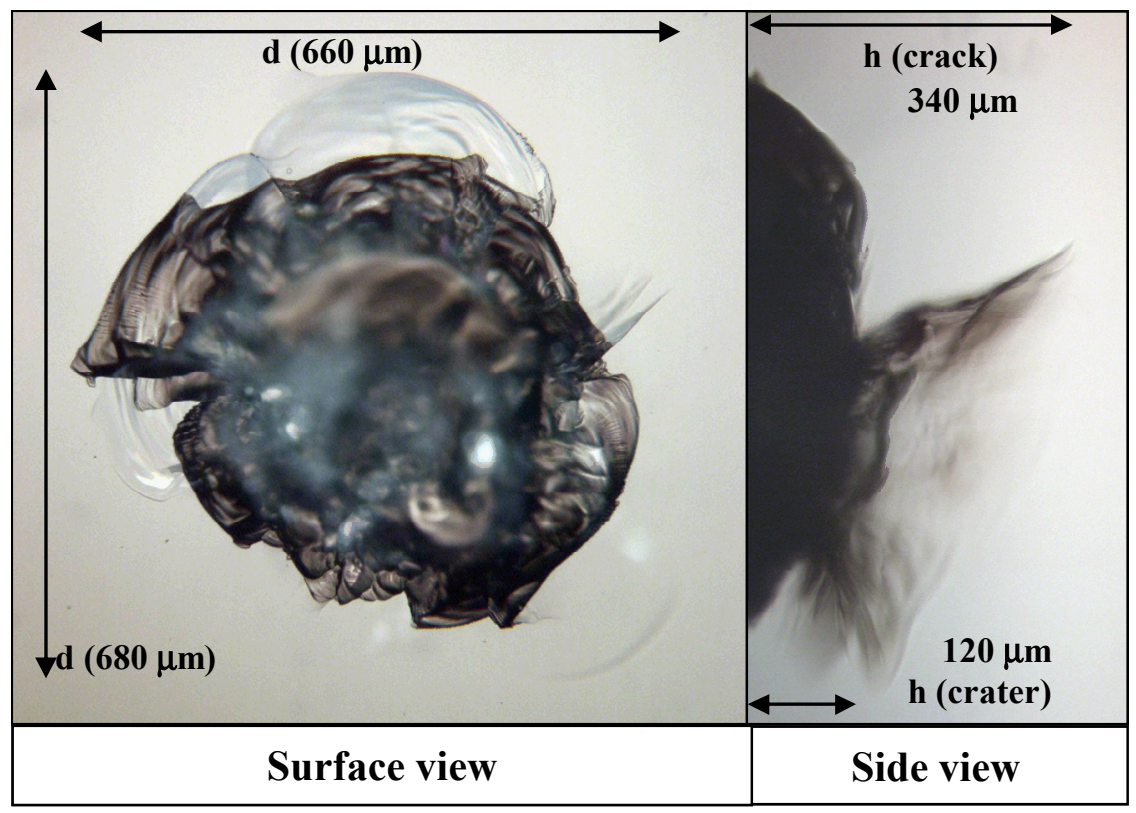

(a)

(b)

Figure 4. Micrographs for a growing site showing both surface and side looking views.

For this site shown in figure 4 the effective diameter is $670 \mu \mathrm{m}$ from which two aspect ratios are calculated: one when viewing the crater the diameter $(\mathrm{d}) / \mathrm{depth}(\mathrm{h})=5.6$ and the other when viewing the crack structure $\mathrm{d} / \mathrm{h}=2.0$.

\subsection{Sequence of diameter and depth images}

It is instructive to look at an entire sequence of images taken for a site which started at $\sim 100 \mu \mathrm{m}$ and grew to $\sim 1500 \mu \mathrm{m}$ as is shown in figure 5. All images are displayed on the same scale, and both surface and side images are included for the initial site and after each shot. The actual starting multipit morphology is shown in figure 7a. This site was shot at a fluence of $8 \mathrm{~J} / \mathrm{cm}^{2}$ of $351 \mathrm{~nm}$ light plus $4 \mathrm{~J} / \mathrm{cm}^{2}$ of $1053 \mathrm{~nm}$ light. By the third shot the underlying crack network consists of a predominant Hertzian cone crack structure along with cracks heading back to the surface. 


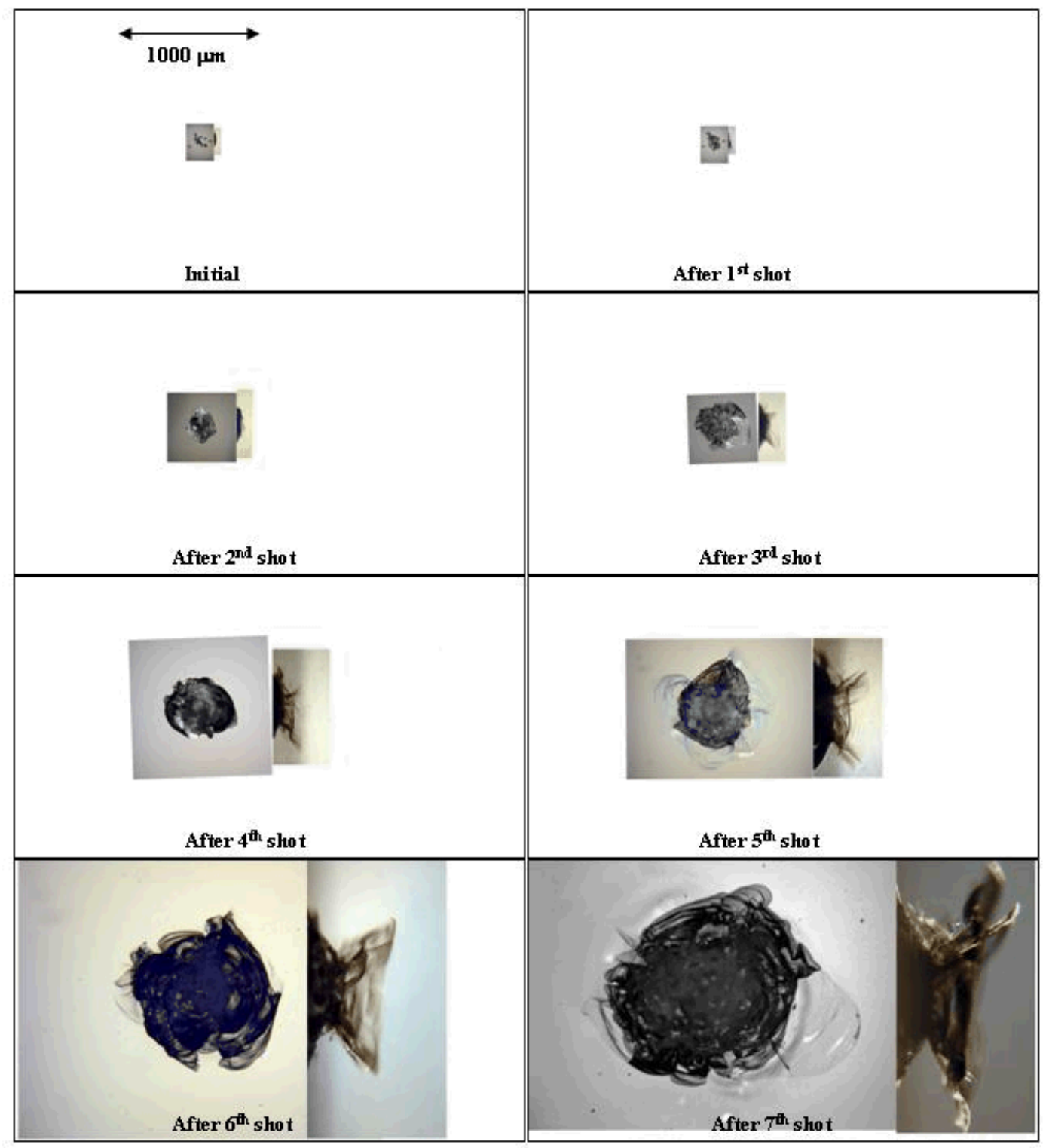

Figure 5. Growth for 7 sequential shots.

\subsection{Diameter \& depth growth curves}

The diameter and the depth of the cracks for the site shown in figure 5 are plotted on the left hand scale vs. shot number in figure 6. Along with the data points a calculated fit to the data sets are shown. We find that, as expected, the diameter growth is well fit to an exponential. In addition, we note that the depth of the cracks can also be fit with an exponential function, though the exponential fit is not as good as that typically obtained for the diameter. The growth certainly is not well described as following a linear dependence on shot number. For all 8 sites studied in these tests the same behavior was observed. Though not shown on this plot we also find that the depth of the crater is also reasonably well described with an exponential function. This near-exponential fit to the depth data was found for all sites whether grown with $351 \mathrm{~nm}$ light or $351 \mathrm{~nm}$ combined with $1053 \mathrm{~nm}$ light. 
On the right hand scale of figure 6 , the ratios for the diameter to depth for both the crater and the cracks are plotted vs. shot number. Both these ratios start out high but within a few shots tend to level out. In our determination of the depth of the sites made with an optical microscope we treat the assemblage of individual pits as a single pit which drives the initial aspect ratio to the large values plotted. Within a few shots the individual nature of the starting pits is no longer discernible. We have developed a technique to obtain both surface and depth SEM images ${ }^{6}$ of laser damage in fused silica. These images show that the starting ratios for a single pit laser damage sites initiated with a single pulse of $351 \mathrm{~nm}, 10 \mathrm{~ns}$, light have aspect ratios of about 5 for the crater and about 3 for the cracks. A comparison of optical micrographs of a newly initiated site utilized in this study and a SEM image of single damage site are shown in figure 7, where the optical image in figure $7 \mathrm{a}$ is typical for those sites used in these tests and the SEM image in figure $7 \mathrm{~b}$ is typical for sites initiated at $10 \mathrm{~ns}$.

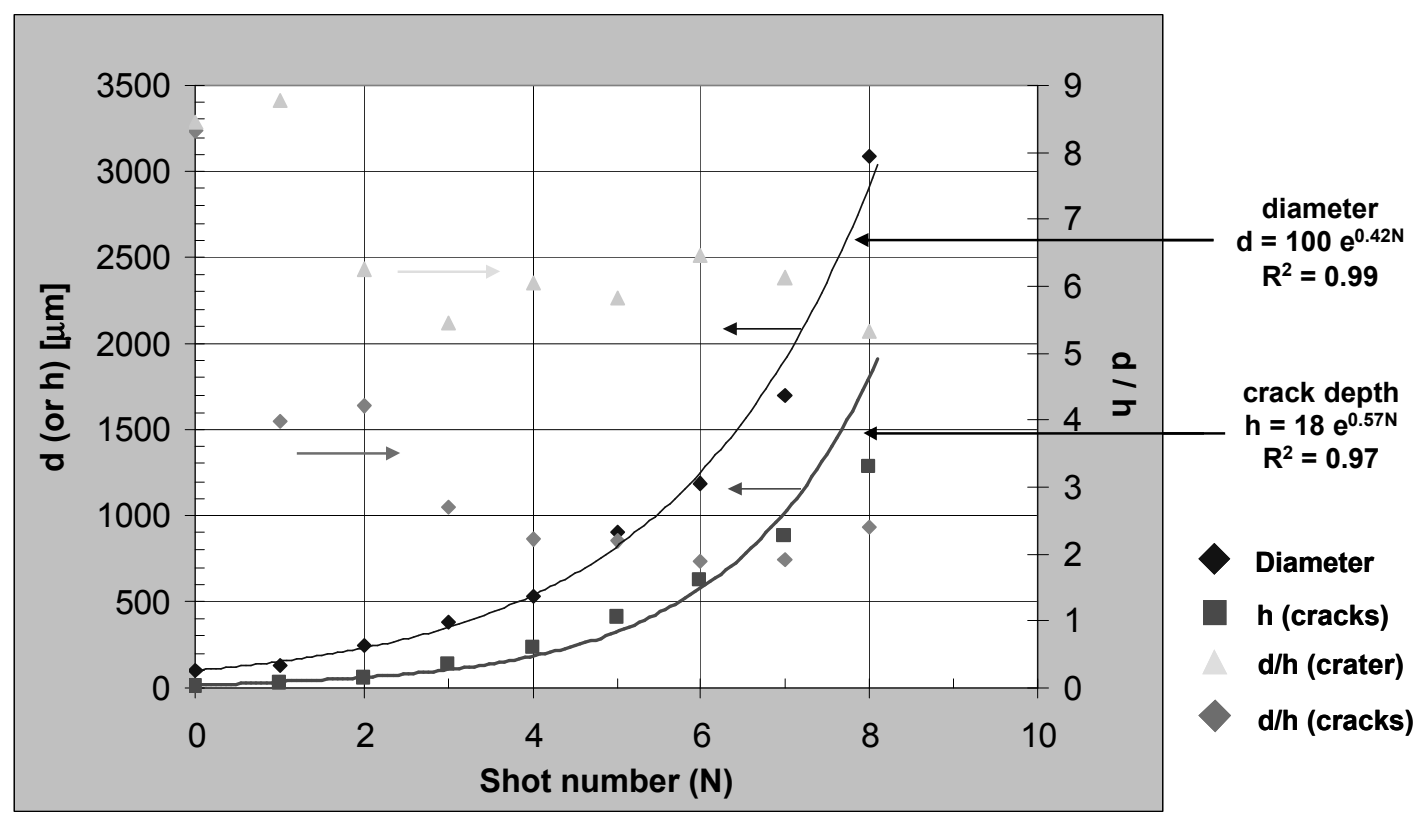

Figure 6. Change in diameter and depth per shot. 


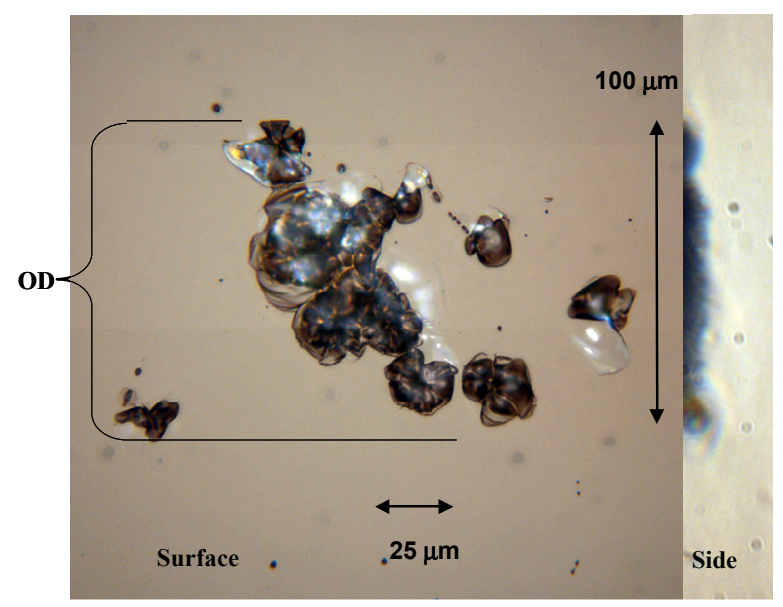

(a)

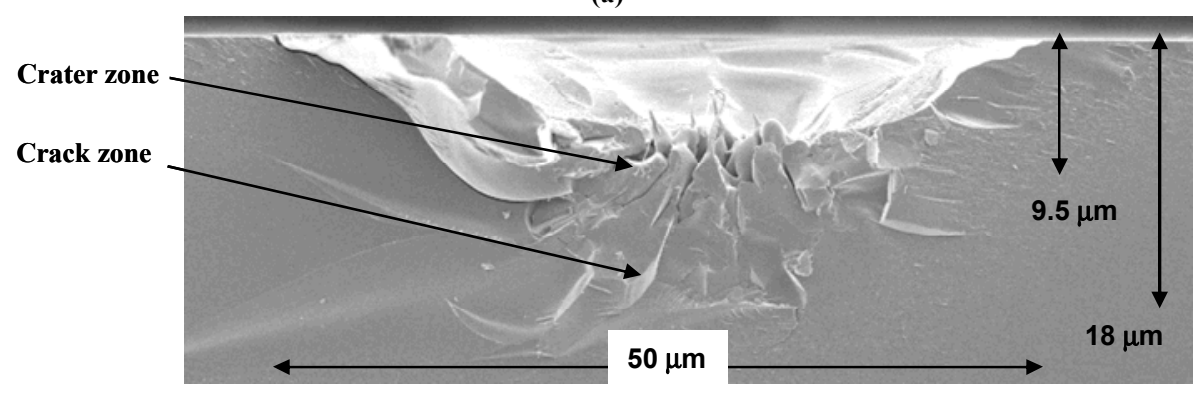

(b)

Figure 7. (a) Optical microscope images of a multipit site and (b) SEM side image of a single pit site.

\subsection{Comparison of diameter and depth growth rates.}

A comparison of the exponential growth rate coefficients for all of the damage sites tested is shown in figure 8, where the crack depth growth coefficient is plotted vs. the lateral diameter growth coefficient. Each data point represents growth rate information for a single site grown at a constant fluence. A straight line fit to the data is also plotted on the graph. The depth exponential growth rate is seen to be about $50 \%$ greater than the diameter exponential growth rate independent of whether the fluence is delivered at $351 \mathrm{~nm}$ or at a combination of $351 \mathrm{~nm}$ and $1053 \mathrm{~nm}$.

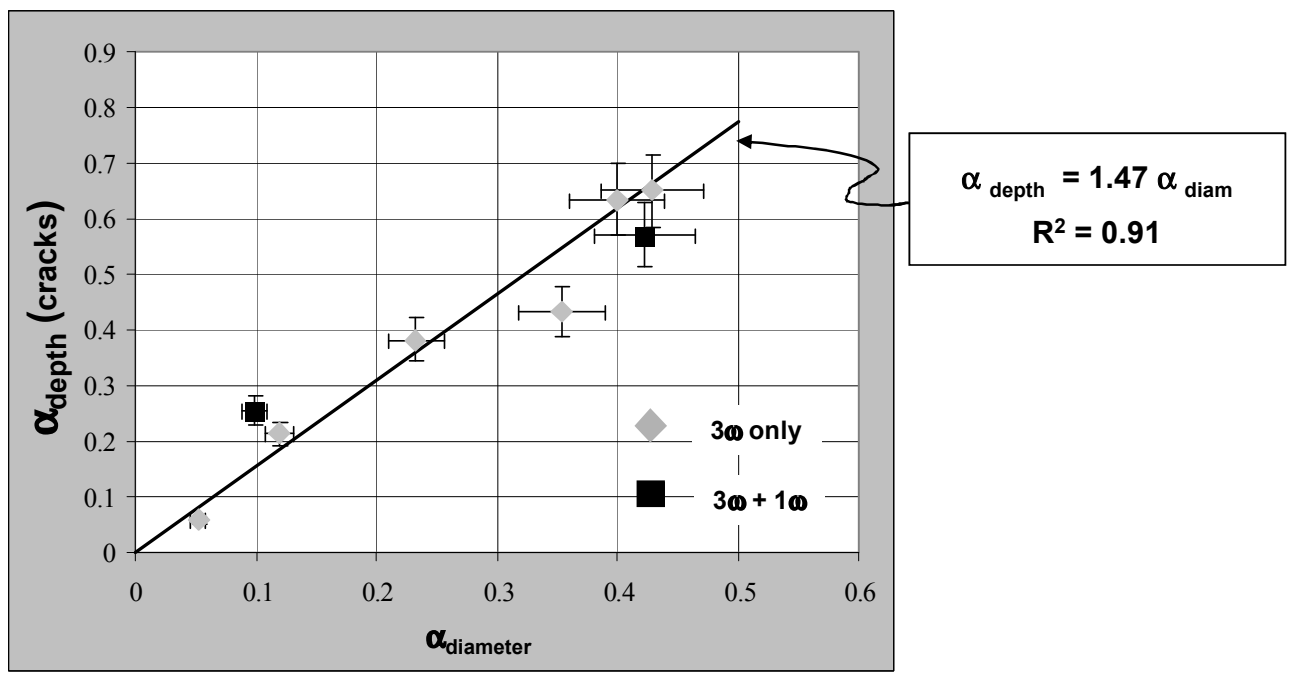

Figure 8. Exit surface growth rate versus crack depth growth rates in fused silica. 


\section{DISCUSSION AND SUMMARY}

The aspect ratios of newly initiated sites as determined by the SEM images indicate that $\mathrm{d} / \mathrm{h}$ is approximately 3 for the crack structure and is approximately 5 for the crater. The aspect ratios measured in this work with the optical microscope yield larger aspect ratios for the starting site but typically within a few shots they are similar to the SEM ratios. At this point, the multi-pit site has coalesced into one site and the resolution of the side images allow for more accurate measurements of the aspect ratios. As the site continues growing we see the aspect ratio continue to decrease. Some sites which grew to diameters over $2 \mathrm{~mm}$ have reached aspect ratios nearing 1 .

We have found that the lateral growth rate of a damage site at constant fluence on the exit surface of fused silica at $351 \mathrm{~nm}$ is well characterized by an exponential dependence on shot number, whereas the depth growth rate is only approximately so characterized, though it is clear that the dependence is stronger than the linear dependence reported earlier $^{1}$. The growth structure beneath the surface must be taken into account when employing mitigation schemes to arrest growth. The measured exponential growth rates for the crack depth are approximately $50 \%$ greater than the exponential growth rates for the diameter. This result is based on the limited data obtained in the course of these measurements. This implies that the aspect ratios should not be leveling off as we have observed.

The $\mathrm{d} / \mathrm{h}$ ratios of a growing site tend to be near two. This can be explained if the absorption of laser energy during exit surface growth results in a near uniform pressure over a region of the surface. Calculated ${ }^{7}$ iso-stress contours for a uniform pressure within a circular region representing the damage site predict ratios as are shown in figure 9 .

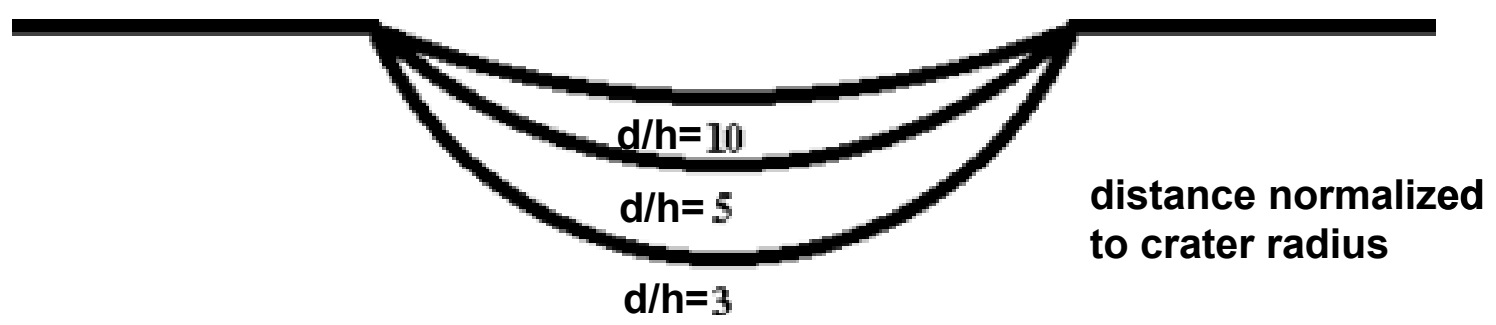

Figure 9. Calculated iso-stress contours for uniform pressure.

The $\mathrm{d} / \mathrm{h}$ ratios correspond to high aspect ratios for weak pressure and for strong pressure approach 2. A unique aspect of exit surface growth is that the laser light passes through and is deposited somewhere inside the material. The resulting plasma formed is more confined than for input surface growth leading to higher pressure and probable modification of the surrounding material. Assuming that the silica fractures and is removed due to high stress, the initial crater formed should correspond to a stress iso-contour as shown in figure 9. On further shots, several effects can occur. First, if the material beneath the crater has been weakened (e. g. by containing cracks), future shots can remove material at a lower stress corresponding to a deeper iso-contour. Further, as the crater is formed, i. e. as the surface becomes curved, the simple picture no longer strictly holds. For the growth conditions realized in these experiments the fluence uniformity is not maintained as the site increases in size over approximately $1 \mathrm{~mm}$; as an example, at the $2 \mathrm{~mm}$ diameter range the central $1-\mathrm{mm}$ region is about 5 to $10 \%$ higher in fluence than the outer $1-\mathrm{mm}$ to $2-\mathrm{mm}$ region. In this case, we have both that the maximum intensity is at the beam center affecting increase of depth more than lateral size and that light impinging on the sides is incident at an angle and less effective than light at the center which is at normal incidence. Eventually, the beam could even be reflected at the crater sides if they are steep enough All of these effects lead to an increased relative effectiveness per shot of depth increase vs. transverse size increase. Future data and/or continuing analysis of the details of growth process may lead to a better understanding of the observed leveling out of the aspect ratios which stands in contradiction to an extrapolation of the measured exponential growth rates.

\section{ACKNOWLEDGEMENTS}

This work was performed under the auspices of the U. S. Department of Energy by Lawrence Livermore National Laboratory under contract DE-AC52-07NA27344. UCRL-PROC-236269 


\section{REFERENCES}

1. M. A. Norton, L. W. Hrubesh, Z. Wu, E. E. Donohue, M. D. Feit, M. R. Kozlowski, D. Milam, K. P. Neeb, W. A. Molander, A. M. Rubenchik, W. D. Sell, and P. J. Wegner, "Growth of laser-initiated damage in fused silica at $351 \mathrm{~nm}$ ", Proc. SPIE 4347, 468, 2000.

2. M. A. Norton, E. E. Donohue, W. G. Hollingsworth, J. N. McElroy, and R. P. Hackel, "Growth of laser-initiated damage in fused silica at $527 \mathrm{~nm}$ ", Proc. SPIE 5273, 236, 2003.

3. M. A. Norton, E. E. Donohue, W. G. Hollingsworth, M. D. Feit, A. M. Rubenchik, and R. P. Hackel, "Growth of laser-initiated damage in fused silica at 1053 nm", Proc. SPIE 5647, 197, 2004.

4. M. A. Norton, E. E. Donohue, M. D. Feit, R. P. Hackel, W. G. Hollingsworth, A. M. Rubenchik, and M. L. Spaeth, "Growth of laser damage in fused $\mathrm{SiO}_{2}$ under multiple wavelength irradiation", Proc. SPIE 5991, 08, 2005.

5. C. B. Dane, L. E. Zapata. W. A. Neuman, M. A. Norton, and L. A. Hackel, "Design and operation of a $150 \mathrm{~W}$ near diffraction-limited laser amplifier with SBS wavefront correction", IEEE J. Quantum Electronics, 31, pp. 148-163, 1995. 6. C. W. Carr, M. J. Matthews, J. D. Bude, and M. L. Spaeth, "The effect of laser pulse duration on laser-induced damage in KDP and $\mathrm{SiO}_{2}$ ", Proc. SPIE 6403, 0K, 2006.

7. A. Nadai, "Theory of flow and fracture of solids", Volume 2, McGraw Hill, 1963. 